\title{
Response spectra for differential motion of columns paper II: Out-of- plane response
}

\section{Introduction}

Common use of the response spectrum method implicitly assumes that all points of building foundations move synchronously and with the same amplitudes. This, in effect, implies that the wave propagation in the soil is neglected. Unless the structure is long (e.g., a bridge with long spans, a dam, a tunnel) or "stiff" relative to the underlying soil, these simplifications are justified and can lead to a selection of approximate design forces, if the effects of soil-foundation interaction in the presence of differential ground motions can be neglected [1]. Simple analyses of two-dimensional models of long buildings suggest that when $a / \lambda<10^{-4}$, where $a$ is wave amplitude and $\lambda$ is the corresponding wavelength, the wave propagation effects on the response of simple structures can be neglected [2].

\footnotetext{
*Corresponding author. Tel.: + 12137400570 .

E-mail address: trifunac@usc.edu (M.D. Trifunac).
}

Figs. 1a and b illustrate the "short" waves propagating along the longitudinal axis of a building or a multiple-span bridge. For simplicity, the incident wave motion has been separated into out-of-plane (OP) motion (Fig. 1a), consisting of $\mathrm{SH}$ and Love waves, and in-plane (IP) motion (Fig. 1b) consisting of P, SV, and Rayleigh waves. The IP motion can further be separated into horizontal (longitudinal), vertical, and rocking components, while OP motion consists of horizontal motion in the transverse direction and torsion along the vertical axis. Trifunac and Todorovska [3] analyzed the effects of the horizontal IP components of differential motion for buildings with models that are analogous to the sketch in Fig. 1b, and they showed how the response spectrum method could be modified to include the first-order effects of differential motion. In the following, we will refer to their paper as Paper I. The purpose of this paper (Paper II) is to show how the response spectrum method can be extended to the case of OP excitation, and when the maximum relative response of a two-degree-of-freedom system can be 

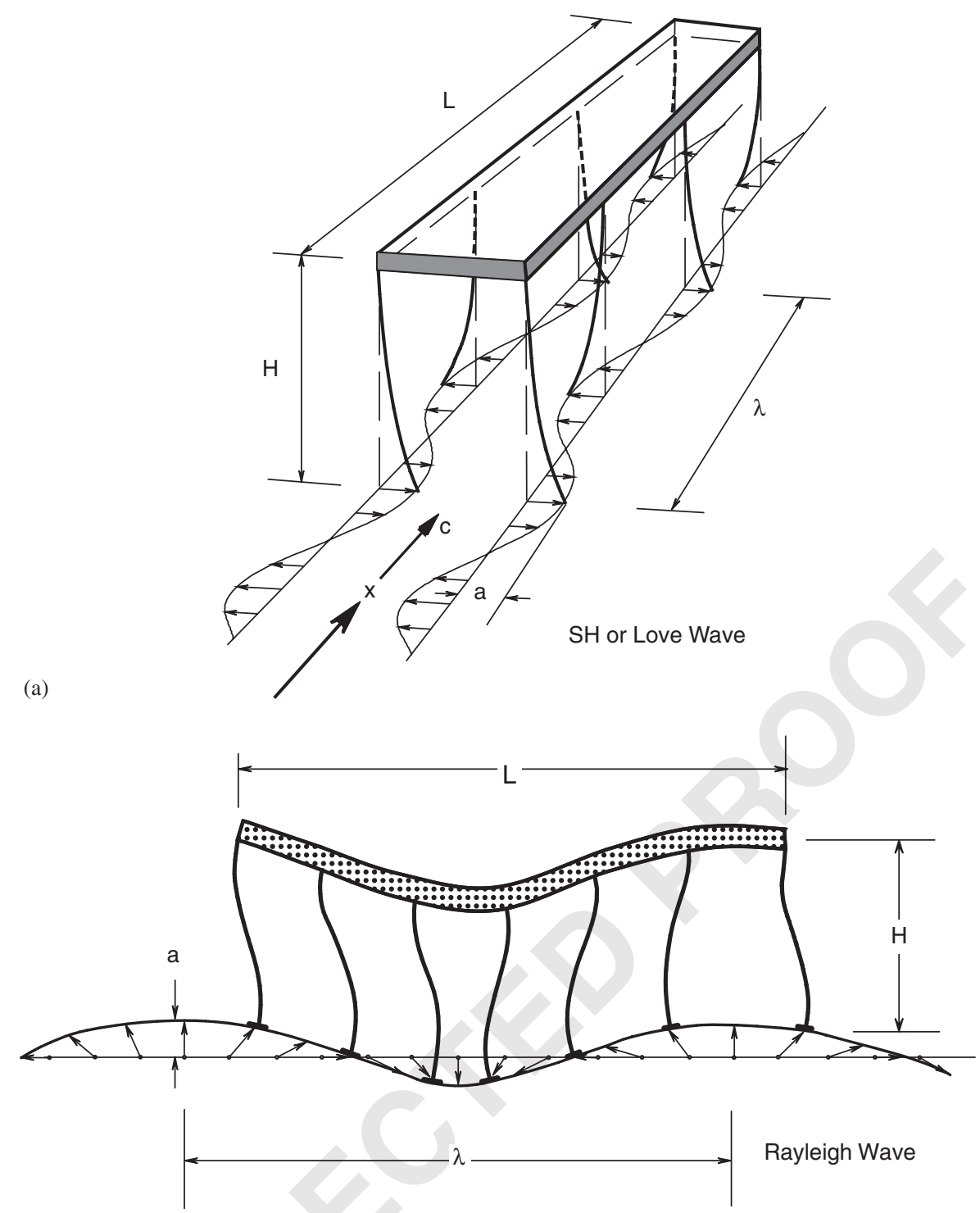

Rayleigh Wave

Fig. 1. (a) A structure excited by passage of a SH or a Love wave. (b) A structure excited by passage of a Rayleigh wave.

approximated by an equivalent spectrum for a single43 degree-of-freedom system response (Fig. 1a).

The concept of modifying response spectra to account

45 for spatial variation of strong ground motion has been addressed in previous studies by describing those variations

47 via a suitable coherency function (e.g. [4]). Other studies which also used coherency function, modeled incoherence

49 of ground motion and propagation effects, but not the frequency dependent wave speeds, and thus no conse-

51 quences of wave dispersion. These coherency-based formulations appear simple and direct, but are far less general

53 than the formulations based on the physical nature of wave propagation, especially in the analyses of response to

55 strong pulses in the near field of earthquake ground 57 only when the physical assumptions it is based on are correct and complete.

In this paper we present a deterministic formulation for the OP response of a two-degree-of-freedom model. We formulate a system of two differential equations, to describe translation and torsion, for the most general ground motion. To show how this solution can be simplified for excitation by long ground waves, we approximate ground torsion in terms of horizontal OP motions, caused by body $\mathrm{SH}$ and surface Love waves. Finally, by using a two-dimensional model and finite differences, we compute response to a propagating pulse of ground displacement, and show how to modify the spectra of translational motions, into a spectrum, which approximates the total (translational and torsional) response. We show that this approximation is valid for strong motion 
1 pulses associated with waves an order of magnitude longer than the structure.

3

5

\section{The model}

The motion of individual column foundations will depend upon the foundation system; the relative stiffness of the soil, connecting beams, and slabs; and the stiffness of the structure supported by the foundation. In general, this motion will have six degrees of freedom (three translations and three rotations) and will depend upon the nature of incident (body and surface) waves and the direction of this incidence. For propagation along the longitudinal axis of the building, SH and Love waves will excite the OP motion and torsion, while the body $\mathrm{P}, \mathrm{SV}$, and surface Rayleigh waves will cause IP horizontal, vertical, and rocking motions. Trifunac and Todorovska [3] have studied horizontal differential motions of column foundations for IP excitation (Fig. 1b) and for long wavelengths of incident waves for which $\lambda \gg L$. In this paper, the approach will be generalized by considering the OP excitation and response only (Fig. 1a). We will analyze the response using a vibrations approach in which $\lambda \gg L$, and we will consider only briefly the wave propagation approach, in which $\lambda$ is comparable to and smaller than $L$. For the general direction of wave incidence, in layered half space, and for linear waves and response, the incident wave motions and the structural response can be decomposed into their IP and OP components, and the total response can be computed by superposition.

As in Paper I, we will neglect the rocking of ground motion in the excitation of individual columns and of the entire foundation system. This rocking excitation may be important for the general azimuth of wave incidence. For OP response, it will vanish only in the special case, considered in this paper, when the wave incidence is along the longitudinal axis of the structure. We will leave analyses of the effects of these rocking excitations for a future study.

\subsection{OP response of one-story structure when $\lambda \gg L$}

The model we consider is shown in Fig. 2. It represents a one-story structure with mass $m$, supported by $n$ columns (see also Fig. 1a), with stiffness $k_{i}=1,2, \ldots, n$. We consider only the OP component of ground motion, $u_{i}(t)$, and of the rigid mass, $u_{\mathrm{r}}(t)$ and $\theta(t)$. The absolute displacements of the tops of the columns are $u_{0}(t)+u_{\mathrm{r}}(t)+x_{i} \theta$, while the absolute displacements of the bases of the columns are $u_{i}$.

We write dynamic equations of equilibrium with respect to a point $R$ (on the ground), which we use as a reference. The OP direction gives

$$
m\left(\ddot{u}_{0}+\ddot{u}_{\mathrm{r}}-e \ddot{\theta}\right)+c \dot{u}_{\mathrm{r}}+\sum_{i=1}^{n} k_{i}\left[u_{\mathrm{r}}+u_{0}+x_{i} \theta-u_{i}\right]=0
$$

while the equilibrium of moments about $A$ gives:

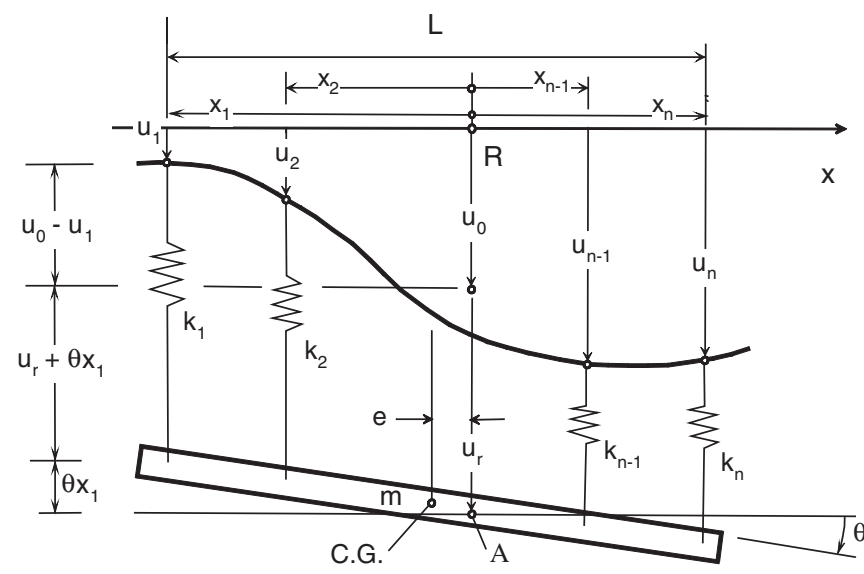

Fig. 2. Simplified two-degree-of-freedom model of a one-story structure in Fig. 1a.

$$
\begin{aligned}
J_{A} \ddot{\theta}- & m e\left(\ddot{u}_{\mathrm{r}}+\ddot{u}_{0}-e \ddot{\theta}\right)+c_{\theta} \dot{\theta} \\
& +\sum_{i=1}^{n} k_{i} x_{i}\left[u_{\mathrm{r}}+u_{0}+x_{i} \theta-u_{i}\right]=0,
\end{aligned}
$$

where $J_{A}$ is the moment of inertia of the rigid mass with respect to point $A$, at distance $e$ from its center of gravity (CG in Fig. 2).

Following the method of Trifunac and Todorovska [3], we choose $u_{0}$, relative to the reference point $R$, so that

$\sum_{i=1}^{n} k_{i}\left(u_{0}-u_{i}\right)=0$

or

$u_{0}=\sum_{i=1}^{n} k_{i} u_{i} / \sum_{i=1}^{n} k_{i}$

It is seen that this definition of $u_{0}$ represents "average" motion of the ground, averaged over length $L$ (Fig. 2), with respect to the weighting factors $k_{i}$. With $u_{0}$ defined by Eq. (3), Eqs. (1) and (2) become

$m \ddot{u}_{\mathrm{r}}+c_{\mathrm{r}} \dot{u}_{\mathrm{r}}+u_{\mathrm{r}} \sum_{i=1}^{n} k_{i}=-m\left(\ddot{u}_{0}-e \ddot{\theta}\right)-\theta \sum_{i=1}^{n} k_{i} x_{i}$

and

$$
\begin{aligned}
J_{A} \ddot{\theta}+c_{\theta} \dot{\theta}+\theta \sum_{i=1}^{n} k_{i} x_{i}^{2}= & m e\left(\ddot{u}_{\mathrm{r}}+\ddot{u}_{0}-e \ddot{\theta}\right)-u_{\mathrm{r}} \sum_{i=1}^{n} k_{i} x_{i} \\
& -\sum_{i=1}^{n} k_{i} x_{i}\left(u_{0}-u_{i}\right),
\end{aligned}
$$

where we have assumed that two "dampers" (with 107 constants $c_{\mathrm{r}}$ and $c_{\theta}$ ) are "connected" between the rigid slab and point $R$ on the ground.

As in Paper I, when distances $x_{i}$ are small relative to the dominant wavelengths of ground motion $\left(\left|x_{1}\right|,\left|x_{2}\right|,\left|x_{3}\right|, \ldots 111\right.$ $\left|x_{n}\right| \ll \lambda_{h}$, where $\lambda_{h}$ is the apparent wavelength along $x$-axis), $u_{i}$ can be approximated by three leading terms in its Taylor 113 series expansion: 


\section{ARTICLE IN PRESS}

4

M.D. Trifunac, V. Gicev / Soil Dynamics and Earthquake Engineering

$1 u_{i}(t) \sim u_{0}(t)+\frac{\partial u}{\partial x} x_{i}+\frac{1}{2} \frac{\partial^{2} u}{\partial x^{2}} x_{i}^{2}$.

3 This gives

$5 u_{0}(t)-u_{i}(t) \sim-\frac{\partial u}{\partial x} x_{i}-\frac{1}{2} \frac{\partial^{2} u}{\partial x^{2}} x_{i}^{2}$.

7

We recall that $\partial u / \partial x$ is the horizontal shear strain in the 9 soil [5]. It also corresponds to the average rotation, $\phi$ (torsion), about the vertical axis between two points

11 separated by distance $x_{i}$. The term $\partial^{2} u / \partial x^{2}$ represents curvature [6], but it can also be approximated by absolute

13 acceleration, normalized by the shear-wave velocity in the soil, $a(t) / \beta^{2}[3]$.

15 Defining

${ }_{17} \tau_{i} \equiv \frac{s x_{i}}{\beta_{\mathrm{av}}}$,

19 where $\beta_{\mathrm{av}}$ is the average shear-wave velocity in the top $30 \mathrm{~m}$ of soil and $s$ is an empirical scaling factor that is of order of

$23 u_{0}(t)-u_{i}(t) \sim v(t) \tau_{i}-\frac{1}{2} a(t) \tau_{i}^{2}$,

25

where $v(t)$ and $a(t)$ are the velocity and acceleration of point $R$ (Fig. 2).

27

The last term on the right-hand side of Eq. $\left(2^{\prime}\right)$ is then

$29 \sum_{i=1}^{n} k_{i}\left(u_{0}-u_{i}\right) x_{i} \sim \sum_{i=1}^{n} k_{i}\left(v(t) \tau_{i}-\frac{1}{2} a(t) \tau_{i}^{2}\right) x_{i}$

$31=\frac{v(t) s}{\beta_{\mathrm{av}}} \sum_{i=1}^{n} k_{i} x_{i}^{2}-\frac{a(t) s^{2}}{2 \beta_{\mathrm{av}}^{2}} \sum_{i=1}^{n} k_{i} x_{i}^{3}$.

33

Dividing Eq. ( $\left.1^{\prime}\right)$ by $m$ and Eq. (2') by $J_{A}$, and defining

35

37

$\omega^{2}=\sum_{i=1}^{n} k_{i} / m$

and

39

${ }_{41} \omega_{\mathrm{T}}^{2}=\sum_{i=1}^{n} k_{i} x_{i}^{2} / J_{A}$.

43

Eq. $\left(1^{\prime}\right)$ and $\left(2^{\prime}\right)$ become

$45 \ddot{u}_{\mathrm{r}}+2 \omega \varsigma \dot{u}_{\mathrm{r}}+\omega^{2} u_{\mathrm{r}}=-\left(\ddot{u}_{0}-e \ddot{\theta}\right)-\frac{\theta}{m} \sum_{i=1}^{n} k_{i} x_{i}$,

47

4

$\ddot{\theta}+2 \omega_{\mathrm{T}} \varsigma_{\mathrm{T}} \dot{\theta}+\omega_{\mathrm{T}}^{2} \theta=\frac{m e}{J_{A}}\left(\ddot{u}_{\mathrm{r}}+\ddot{u}_{0}-e \ddot{\theta}\right)-\frac{u_{\mathrm{r}}}{J_{A}} \sum_{i=1}^{n} k_{i} x_{i}$

51

$-\omega_{\mathrm{T}}^{2}\left(\frac{v(t) s}{\beta_{\mathrm{av}}}-\frac{a(t) s^{2}}{r \beta_{\mathrm{av}}^{2}} \xi\right)$,

53 where

$55 \zeta \equiv 2 c / c_{\mathrm{cr}}$,

$57 \zeta_{\mathrm{T}} \equiv c_{\mathrm{T}} / c_{\mathrm{T}, \mathrm{cr}}$, $c_{\mathrm{cr}} \equiv 2\left(m \sum_{i=1}^{n} k_{i}\right)^{1 / 2}$

$c_{\mathrm{T}, \mathrm{cr}}=2\left(J_{A} \sum_{i=1}^{n} k_{i} x_{i}^{2}\right)^{1 / 2}$

and

$\xi \equiv \sum_{i=1}^{n} k_{i} x_{i}^{3} / \sum_{i=1}^{n} k_{i} x_{i}^{2}$

61

For a symmetric structure $e=0, J_{A}=J$ (moment of inertia of the rigid mass with respect to $\mathrm{CG}$ ), $\xi=0$ and $\sum_{i=1}^{n} k_{i} x_{i}=0$, and Eq. (1") and Eq. (2") simplify to

$\ddot{u}_{\mathrm{r}}+2 \omega \zeta \dot{u}_{\mathrm{r}}+\omega^{2} u_{\mathrm{r}}=-\ddot{u}_{0}$,

$\ddot{\theta}+2 \omega_{\mathrm{T}} \zeta_{\mathrm{T}} \dot{\theta}+\omega_{\mathrm{T}}^{2} \theta=+\omega_{\mathrm{T}}^{2} \phi_{0}$,

where

$\phi_{0}(t) \sim \frac{-v(t) s}{\beta_{\mathrm{av}}}$.

In Eq. (14), $\mathrm{s}$ is analogous to $A$, which is discussed in Paper I for IP motion and serves to approximate the "equivalent" overall phase velocity $c_{\text {eqiv }}$ via $c_{\text {eqiv }} \approx \beta_{\text {av }} / s$. The idea here is that the complexity of the analysis can be reduced if some equivalent phase velocity $c_{\text {eqiv. }}$ can be used in place of all surface-wave modes and all body waves propagating along the supports of the structure. We assume it is possible to define $c_{\text {eqiv. }}$ and then choose $s=\beta_{\text {av }} / c_{\text {eqiv }}$ because it is convenient to relate $c_{\text {eqiv. }}$ to the average velocity of shear waves in the top $30 \mathrm{~m}, \beta_{\mathrm{av}}$, which can be determined from site investigations. For incident $\mathrm{SH}$ waves, $c_{\text {eqiv. }}$ will depend upon $\beta_{\text {av }}$ and upon the incident angle $\gamma$ between the incident ray and the vertical $\left(c_{\text {eqiv. }} \sim \beta_{\text {av }} /\right.$ $\sin \gamma$ ). For soft surface soil/sediments and incident body waves, $\gamma \rightarrow 0$, and thus $c_{\text {eqiv. }}$ may be in the range say from 1 to $6 \mathrm{~km} / \mathrm{s}$. The contribution of surface waves will dominate at larger epicentral distances and for shallow faulting [7-9]. It can be seen from this that further research is required to develop a robust empirical scaling equation for $s$.

The shear forces $V_{i}(i=1,2, \ldots, n)$ in the columns of the one-story structure (Fig. 2) are

$V_{i}=k_{i}\left[u_{0}(t)+u_{r}(t)+\theta(t) x_{i}-u_{i}(t)\right]$,

and since $u_{i}(t)=u_{0}(t)-v(t) \tau_{i}+\frac{1}{2} a(t) \tau_{i}^{2}$

$V_{i}=k_{i}\left[u_{\mathrm{r}}(t)+\theta(t) x_{i}+v(t) \tau_{i}-\frac{1}{2} a(t) \tau_{i}^{2}\right]$,

where $v(t)$ and $a(t)$ are the ground velocity and ground acceleration for reference point $R, v(t)=\partial u_{0}(t) / \partial t$ and $a(t)=\partial^{2} u_{0}(t) / \partial t^{2}$.

To design the columns for maximum shear, the maximum relative displacement of the columns has to be estimated. For this purpose, we define a five-parameter relative displacement spectrum for columns $\operatorname{SDC}\left(T, T_{\mathrm{T}}, \zeta\right.$, $\left.\zeta_{\mathrm{T}}, \tau\right)$ by 
$1 \quad \operatorname{SDC}\left(T, T_{\mathrm{T}}, \zeta, \zeta_{\mathrm{T}}, \tau\right) \equiv \max _{\forall t}$

$$
\left[u_{\mathrm{r}}(t)+\theta(t) x_{i}+v(t) \tau-\frac{1}{2} a(t) \tau^{2}\right] \text {, }
$$

where $T=2 \pi / \omega, T_{\mathrm{T}}=2 \pi / \omega_{\mathrm{T}}$ and $\zeta$ and $\zeta_{\mathrm{T}}$ are given by Eqs. (9) and (10), respectively.

The maxima of $V_{i}(t), u_{\mathrm{r}}(t), \theta(t), \phi_{0}(t), v(t)$ and $a(t)$, in general all occur at different times. Assuming that

$\theta_{\max } x_{i} \sim v_{\max } \tau_{i}$, neglecting the contribution of $a(t)$, and using square root of the sum of squares approximation, it follows that

$\operatorname{SDC}\left(T, T_{\mathrm{T}}, \zeta, \zeta_{\mathrm{T}}, \tau\right) \approx\left\{u_{\mathrm{r}_{\max }}^{2}+2\left(v_{\max } \tau\right)^{2}\right\}^{1 / 2}$

and

$V_{i_{\max }} \approx k_{i} \operatorname{SDC}\left(T, T_{\mathrm{T}}, \zeta, \zeta_{\mathrm{T}}, \tau\right)$

\section{Torsional strong ground motion}

The rotation of the ground surface about vertical axis $z$ associated with motions $u_{x}$ and $u_{y}$ in the $x$-and $y$-directions (Fig. 3) is equal to

$\phi=\frac{\partial u_{y}}{\partial x}-\frac{\partial u_{x}}{\partial y}$.

In this paper, we assume the presence of SH and Love waves only, propagating in the $x$ direction (so that $u_{x}=0$ ), and we express the rotation $\phi$ by [10]

$\phi=\frac{\partial u_{y}}{\partial x}$.

For harmonic-wave motion, $u_{y}=A \mathrm{e}^{i \omega\left(t-\left(x / c_{x}\right)\right)}$, and $\phi=$ $-A\left(\omega / c_{x}\right) \mathrm{e}^{i \omega\left(t-x / c_{x}\right)}$ and for velocity $v_{y}=\partial u_{y} / \partial t=$ $A \omega \mathrm{e}^{i \omega\left(t-\left(x / c_{x}\right)\right)}$ this gives $\phi=-v_{y} / c_{x}$. For strong earthquake ground motion, which is a superposition of many harmonic waves with different phase velocities, we assume that the rotation $\phi(t)$ in Eq. (20) can be approximated by $\phi_{0}(t)$,

$\phi_{0}(t)=-v_{y}(t) / c_{\text {eqiv. }}$,

where $c_{\text {eqiv }}$ is some "average" or "representative" phase

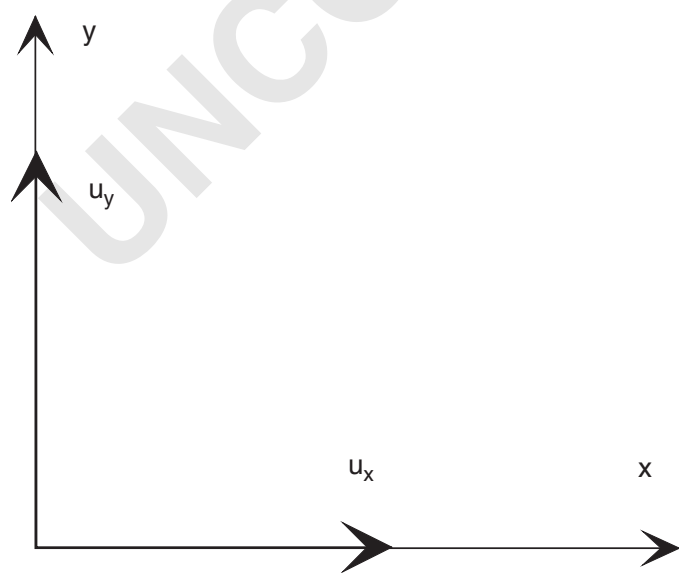

Fig. 3. Coordinates $x$ and $y$ and displacements $u_{x}$ and $u_{y}$. velocity, $c_{\min }<c_{\text {eqiv. }}<c_{\max }$, and $c_{\min }$ and $c_{\max }$ are the minimum and maximum phase velocities at a site with parallel layers (Fig. 4). Throughout this paper, in order to simplify notation we will drop the subscript " $y$ " and use $u$ in place of $u_{y}$ and $v$ in place of $v_{y}$.

Approximation in terms of Eq. (21) cannot be verified by comparison with recorded data because strong-motion torsional accelerograms $\ddot{\phi}(t)$ and velocities $\dot{\phi}(t)$ have not been recorded thus far [12]. However, for a layered half space and linear wave propagation, this approximation can be tested by comparison with synthetically computed $\omega_{z}$ and $v(t)$, where $\omega_{z}=(1 / 2)\left(\left(\partial u_{y} / \partial x\right)-\left(\partial u_{x} / \partial y\right)\right)=\frac{1}{2} \phi$ $[11,13,14]$. We illustrate this by considering artificial translational $\left(\partial^{2} u / \partial t^{2}\right)$ and torsional $\left(\partial^{2} \omega_{z} / \partial t^{2}\right)$ accelerograms, computed for a hypothetical earthquake, with magnitude $M=6.5$, at epicentral distance $R=10 \mathrm{~km}$, and for horizontal $u(t)$ and torsional $\phi(t)=2 \omega_{z}(t)$ motions evaluated for a layered half space model at the El Centro, California, site (Fig. 4 in [11]). This comparison is shown in Fig. 5, where $v(t)$ and $\phi(t)=2 \omega_{z}(t)$ are computed by a synthesis of surface and body waves. It is seen from this example that Eq. (21) can represent a reasonable approximation, provided a suitable phase velocity $c_{\text {eqiv. }}$. can be chosen.

The scales chosen in Fig. 5, for comparison of $-v(t)$ with $\phi(t)$ are equivalent to $c_{\text {eqiv. }}=2 \times 3000 \mathrm{~m} / \mathrm{s}$. In this figure
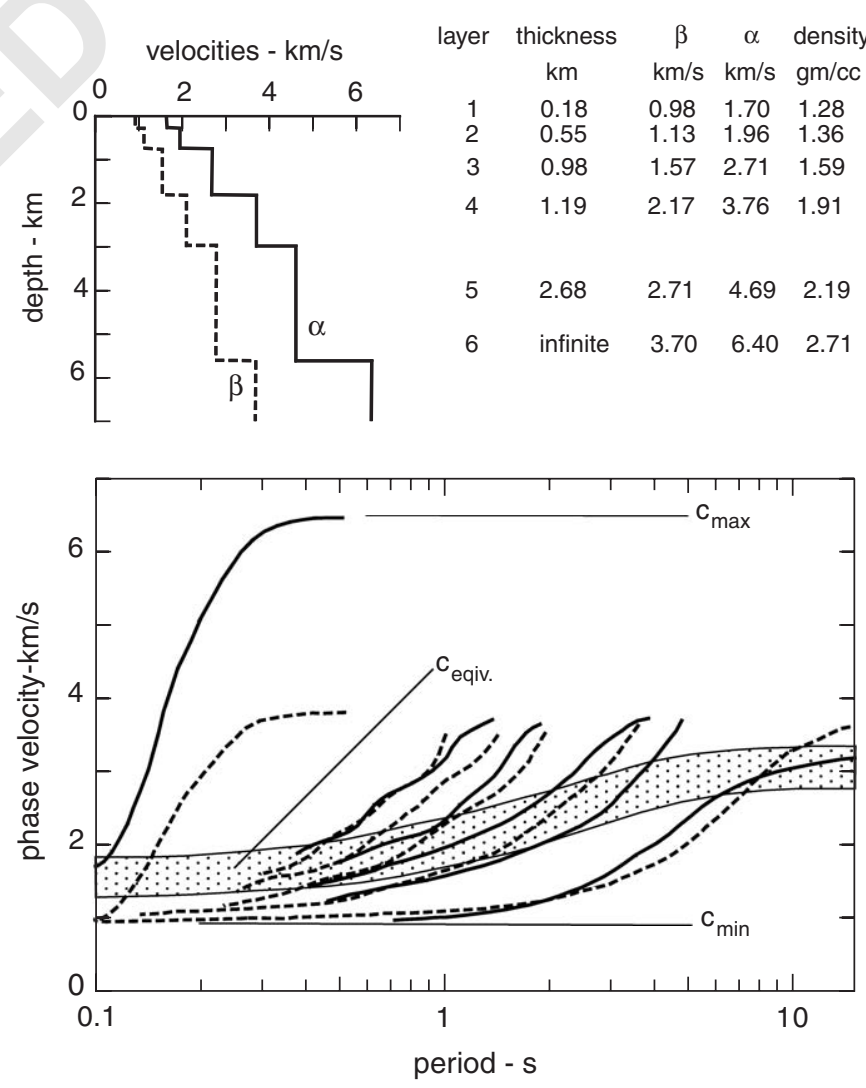

101

103

105

107

Fig. 4. (top) Typical variation of $P$-wave $(\alpha)$ and $S$-wave $(\beta)$ velocities versus depth in El Centro, Imperial Valley, California; and (bottom) the corresponding Love (dashed lines) and Rayleigh (full lines) phase velocities (redrawn from [11]). 


\section{ARTICLE IN PRESS}

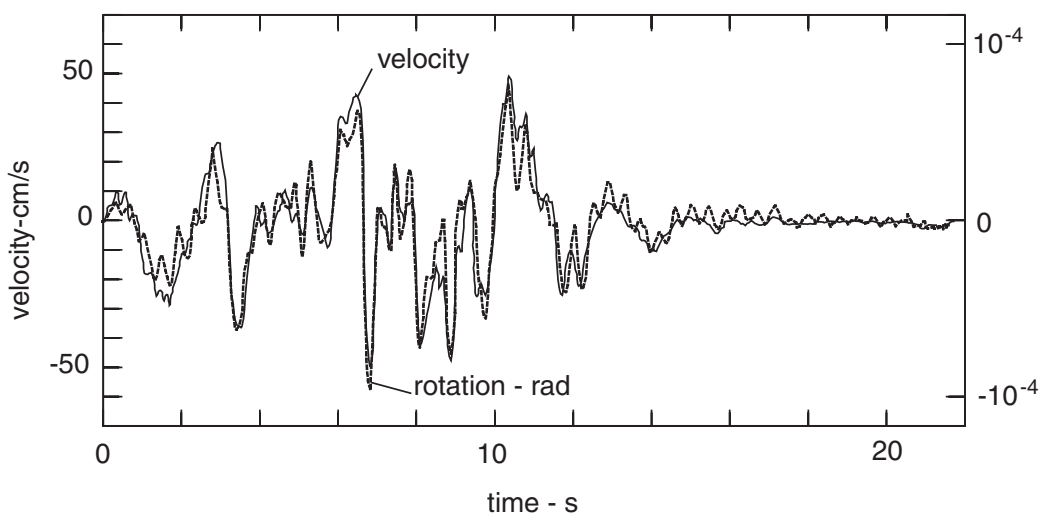

Fig. 5. Comparison of synthetic ground velocity and the associated torsional rotation (see Figs. 4 and 6 in [11]).

we show a synthetic torsional accelerogram $\phi(t)=2 \omega_{z}(t)$

19 and velocity $v(t)$ computed by Lee and Trifunac [11], and for $v(t)$ consisting of $\mathrm{SH}$ and Love waves only. In these

21 synthetic calculations, because of idealized representation of half space, it is possible to compute separately radial and

23 vertical accelrograms (accompanied by rocking; [15]) and transverse translational accelerogram (accompanied by 25 torsion, [11]).

It can be seen from Fig. 5 that for the long-period

27 components $(T>3 s) v(t)$ and $\phi(t)$ agree well, when $c_{\text {eqiv. }}=3000 \mathrm{~m} / \mathrm{s}$. For intermediate and short periods

$29(T<1 s)$ motions, however, $c_{\text {eqiv. }}$ should be smaller, decreasing from $c_{\text {eqiv. }} \approx 2000 \mathrm{~m} / \mathrm{s}$ near $T=1 \mathrm{~s}$ toward

$31 c_{\text {eqiv. }}=1 \mathrm{~km} / \mathrm{s}$ as $T \rightarrow 0$. In the examples of computed spectra in this paper we will use the oscillator periods $T$ in

33 the range from 0.04 to $6.0 \mathrm{~s}$, and will assume that the torsional frequency is $\sqrt{3}$ times the translational frequency.

35 For an average $\bar{c}_{\text {eqiv. }}=1.5 \mathrm{~km} / \mathrm{s}$ and $c_{\min }=\beta_{\text {av }}=0.98 \mathrm{~km} /$ $\mathrm{s}, s \sim 0.65$. Obviously, if $c_{\text {eqiv. }}=c_{\text {eqiv. }}(\omega), s$ in Eq. (5) should

37 also be a function of frequency. The empirical studies on how $c_{\text {eqiv. }}$ and $s$ should depend upon frequency and other

39 site and earthquake parameters will be the subject of our future investigations. At present, this subject can be

41 approached only though the theoretical and synthetic representation of dispersed strong-motion waves. Empiri-

43 cal estimation of $s$ will become possible in the future when a sufficient number of recorded rotational accelerograms

45 becomes available.

\section{4. Multi-story buildings}

49 Trifunac and Todorovska [3] have shown that the maximum, relative, IP displacement of the $i$ th first-story

51 column of a building responding to differential (horizontal 53 only) ground motion can be approximated by$$
\mathrm{SDC}_{i}^{\mathrm{IP}} \approx\left\{E^{2}\left[d_{1}^{\mathrm{IP}}(t)_{\max }\right]+\left(v_{\max }^{\mathrm{IP}} \tau_{i}\right)^{2}+\left(\frac{1}{2} a_{\max }^{\mathrm{IP}} \tau_{i}^{2}\right)^{2}\right\}^{1 / 2},
$$

where $d_{1}(t)$ is the displacement of the first floor, neglecting soil-structure interaction, rotational components of strongmotion, and modal interaction [16-19].

\subsection{Response spectra for first-story columns and $O P$ response}

In the following, we assume that there is no coupling of $\mathrm{OP}$ and torsional responses of a multi-story-building. Then the above Eq. (22) can be generalized to estimate the maximum relative displacement of the $i$ th first-story column as follows:

$$
\begin{aligned}
\operatorname{SDC}_{i}^{\mathrm{OP}} \approx & \left\{E^{2}\left[d_{1}^{\mathrm{OP}}(t)_{\max }\right]+E^{2}\left[\left(\theta_{1}^{\mathrm{OP}}(t)\right)_{\max } x_{i}\right]\right. \\
& \left.+\left(v_{\max }^{\mathrm{OP}} \tau_{i}\right)^{2}+\left(\frac{1}{2} a_{\max }^{\mathrm{OP}} \tau_{i}^{2}\right)^{2}\right\}^{1 / 2},
\end{aligned}
$$

where $d_{1}^{\mathrm{OP}}(t)$ is the OP relative response of the first-story (proportional to $u_{\mathrm{r}}$ ) and $\theta_{1}^{\mathrm{OP}}(t)$ is the relative rotation, also of the first floor only, of a multi-story structure corresponding to $u_{\mathrm{r}}$ and $\theta$ in the equivalent two-degree-offreedom system (Fig. 2). $v_{\max }^{\mathrm{OP}}$ and $a_{\max }^{\mathrm{OP}}$ are peak ground velocity and peak ground acceleration in OP directions, respectively. As in Eq. (22), Eq. (23) neglects contributions from soil-structure interaction and modal interaction. As noted by Trifunac and Todorovska [3], all of those contributions can be included, after some generalizations of the probabilistic representation of the response-toearthquake excitation. Such generalizations are outside the scope of this paper, and thus we present here only the basic concepts for the design of first-story columns.

\subsection{First mode approximation}

For multi-story buildings, which respond mainly in the first mode of vibration, it is possible to approximate relative displacement of the first-story columns in terms of parameter $\delta$, which represents the normalized amplitude of the first mode shape at the first floor [3], as in 
$\delta \approx \begin{cases}1.27 \sin \left(\frac{\pi}{2 N}\right) & \text { (assuming sinusoidal mode shape) } \\ 1.5 / N & \text { (assuming straight line mode shape) }\end{cases}$

where $N$ is the number of stories. Assuming that $T_{1} \sim N / 10$, and adopting the straight mode shape approximation, $\delta$ can be expressed as [3]

$\delta \approx \begin{cases}1.5 /\left(10 T_{1}\right) & T_{1} \geqslant 0.15 \\ 1 & T_{1}<0.15,\end{cases}$

where $T_{1}$ is the period of the fundamental mode of vibration.

In the following we assume that the first torsional mode shape of a symmetric building can also be approximated by a straight line. Then the relative displacement spectrum for the first-story columns for OP response can be approximated by

$$
\begin{aligned}
\operatorname{SDC}_{i}\left(T, T_{\mathrm{T}}, \zeta, \zeta_{\mathrm{T}}, \tau, \delta\right) \approx\left[\delta u_{\mathrm{r}}(t)+\delta \theta(t) x_{i}\right. \\
\left.+v(t) \tau_{i}-\frac{1}{2} a(t) \tau_{i}^{2}\right] .(26)
\end{aligned}
$$

From Eq. $\left(2^{\prime \prime \prime}\right)$ it is seen that for $\omega_{\mathrm{T}} \gg 1$, $|\theta(t)|_{\max } \sim\left|v_{\max }\right| / c_{\text {eqiv }}$. Also, $|\theta(t)|_{\max } x_{i} \sim|v|_{\max } x_{i} / c_{\text {eqiv. }} \sim\left|v_{\max }\right| \tau_{i}$. Then, neglecting the contribution of the last term in Eq. (26), we can approximate Eq. (26) by

$$
\begin{aligned}
\operatorname{SDC}_{i}\left(T, T_{\mathrm{T}}, \zeta, \zeta_{\mathrm{T}}, \tau, \delta\right) \approx & \left\{\delta^{2} \operatorname{SD}^{2}(T, \zeta)\right. \\
& \left.+(1+\delta)\left(v_{\max } \tau_{i}\right)^{2}\right\}^{1 / 2} .
\end{aligned}
$$

\subsection{Computation of $\operatorname{SDC}\left(T, T_{T}, \zeta, \zeta_{T}, T\right)$}

Computation of $\operatorname{SDC}\left(T, T_{\mathrm{T}}, \zeta, \zeta_{\mathrm{T}}, \tau, \delta\right)$ for the OP response requires simultaneous numerical integration of differential Eq. (1"') and Eq. (2"') for given values of $\omega, \omega_{\mathrm{T}}$,

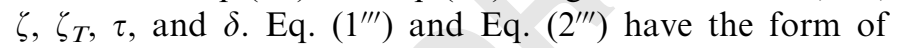
classical constant-coefficient, linear, second-order differential equations specifying the response of a single-degree-offreedom system. Therefore, we use the well-established procedures for computation of response spectra, which are described in Trifunac and Lee [20,21]. These procedures apply directly to Eq. $\left(1^{\prime \prime \prime}\right)$, and the required input is the standard data file specifying absolute ground acceleration on ground surface $\ddot{u}_{0}(t)$ versus time.

Since $\phi_{0}(t) \sim-v(t) s / \beta_{\mathrm{av}}$, before solving Eq. ( $\left.2^{\prime \prime \prime}\right)$ we "multiply" both sides by $\beta_{\mathrm{av}} / s$ and then solve

$\ddot{\xi}+2 \omega_{\mathrm{T}} \zeta_{\mathrm{T}} \dot{\xi}+\omega_{\mathrm{T}}^{2} \xi=+\omega_{\mathrm{T}}^{2} v(t)$.

After Eq. (28) has been solved for given $\omega_{\mathrm{T}}$ and $\zeta_{\mathrm{T}}$, to compute $\theta(t) x_{i}$ we multiply $\xi(t)$ by $\tau_{i}=s x_{i} / \beta_{\mathrm{av}}$. It is seen that this procedure allows us to compute the contribution of $\theta(t) x_{i}$ to Eqs. $\left(15^{\prime}\right)$ and (16) as $\xi(t) \tau$. In other words, it is not necessary to specify the detailed geometry of the structure (i.e., $x_{i}$ ). The complete formulation can be carried out in terms of general values of the parameter $\tau$.

\section{Results and analysis}

The relative response $\left|u_{\mathrm{r}}\right|_{\max }$ increases with the period of the SDOF system, $T=2 \pi / \omega$, and as $T \rightarrow \infty$, $\left|u_{\mathrm{r}}(t)\right|_{\max } \rightarrow\left|u_{0}(t)\right|_{\max }$. The relative displacement spectrum $\mathrm{SD}(T, \zeta)=\max _{y}\left|u_{r}(t)\right|$ thus increases from zero to $\left|u_{0}(t)\right|_{\max }$ as $T$ changes from zero to infinity. This is shown in Fig. 6 , which illustrates $\operatorname{SD}(T, \zeta)$ for the $\operatorname{SDOF}$ system $(\delta=1)$ and for $\zeta=0.05$, for the S16W component of strong-motion acceleration recorded during the Northridge, California, earthquake of January 17, 1994, at Station \#53 of the University of Southern California (USC) Los Angeles

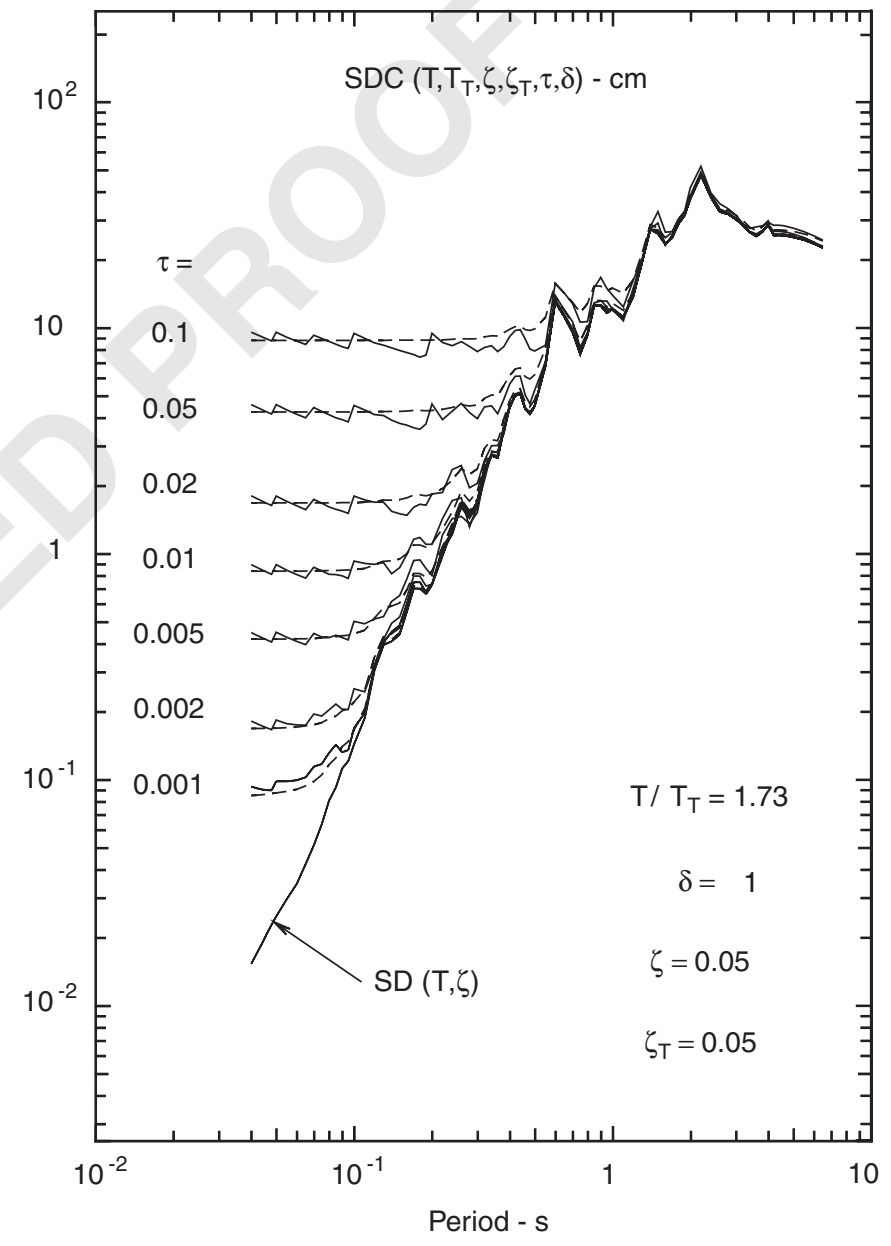

Fig. 6. The newly defined SDC spectra for the S16W component of the accelerogram recorded at station \#53 of the Los Angeles Story Motion Network during the Northridge, CA earthquake of 17 January 1994 $(M=6.7)$, at epicentral distance $6 \mathrm{~km}$. All spectra correspond to damping ratio $\zeta=0.05$ and to $\delta=1$ (one-story building). Different spectra correspond to different values of parameter $\tau=S x / \beta_{\text {av }}$ ranging from 0.001 to 0.1 . $x$ is the distance of the column from point $R$ in the undeformed configuration, and $\beta_{\text {av }}$ is the average shear wave velocity in the top $30 \mathrm{~m}$ of soil. The solid lines correspond to SDC-spectra calculated exactly, and the dashed lines to the approximate estimate via relative spectral displacement $\mathrm{SD}$, also shown in the figure, and the peak ground velocity and acceleration. 


\section{ARTICLE IN PRESS}

1 Strong-motion Network [22]. This figure also shows spectra of maximum relative displacement of columns

$3 \operatorname{SDC}\left(T, T_{\mathrm{T}}, \zeta, \zeta_{\mathrm{T}}, \tau, \delta\right)$ for $\delta=1, \zeta=\zeta_{\mathrm{T}}=0.05$, and $\tau$ in the range from 0.001 to 0.1 (for the $i$ th column, at distance

$5 x_{i}$ from the reference point $\left.R, \tau_{i}=s x_{i} / \beta_{\mathrm{av}}\right)$. The solid lines correspond to SDC spectra computed from Eq. (26), and

7 the dashed lines show approximate values of SDC computed from Eq. (27).

9 For the S16W component of strong-motion recorded at USC station $\# 53$, peak amplitudes were $u_{0_{\max }}=12.4 \mathrm{~cm}$

$11 v_{\max }=59.8 \mathrm{~cm} / \mathrm{s}$, and $a_{\max }=381 \mathrm{~cm} / \mathrm{s}^{2}$ (4.88 in., 23.5 and $150 \mathrm{in} . / \mathrm{s}^{2}$, respectively). Fig. 6 shows that the short period

13 amplitudes of SDC tend toward a constant. For these short periods, the peak relative displacement of the columns is

15 dominated by $(1+\delta) v_{\max } \tau$ and the peak shear forces in the first-story columns will result from this pseudo-static

17 deformation caused by differential motions.

Fig. 6 has the same appearance as Fig. 6 in Trifunac and

19 Todorovska [3] except that the amplitudes of the constant regions of SDC now have larger amplitudes because of the

21 contribution from torsional response. For short periods, where the pseudo static terms dominate in the response,

23 this factor of increase is equal to $1+\delta$. For $\delta=1$, this is equal to 2.0.

25 Fig. 7 shows the amplitude factor $\operatorname{SDC}\left(T, T_{\mathrm{T}}, \zeta, \zeta_{\mathrm{T}}, \tau, \delta\right) /$ $\delta \mathrm{SD}(T, \zeta)$ for $\zeta=\zeta_{\mathrm{T}}=0.05, \delta=1$, with $\tau$ in the range

$270.001-0.1$, and for $T / T_{\mathrm{T}}=1.73$. For $T=0.1 \mathrm{~s}$, for example, this factor is in the range 1.1 (for $\tau=0.001$ ) to

2965 (for $\tau=0.1$ ). If we consider the same example as in [3] one-story building with natural period $T \sim 0.1 \mathrm{~s}$, torsional

31 period $T_{\mathrm{T}}=0.058$, damping $\zeta=\zeta_{\mathrm{T}}=0.05$, at a site with $\beta_{\mathrm{av}}=300 \mathrm{~m} / \mathrm{s}$ and with building plan dimensions equal to

$3330 \mathrm{~m})$ we will have $\tau_{\max }=1 . \times 15 . / 300=0.05$, and the amplification factor for OP response, combined with the

35 contribution from torsional response, $\operatorname{SDC}(0.1,0.058$, $0.05,0.05,0.05,1.0) / \mathrm{SD}(0.1,0.05) \approx 32$. For IP response

37 (longitudinal) and for the same hypothetical example, Trifunac and Todorovska [3] estimated the amplification

39 factor for the largest shear in the columns to be about 20. Soil structure interaction, combined with the non-linear

41 response of the soil and structure, may change these factors significantly, but these large factors nevertheless help

43 explain why the corner columns of long and stiff structures often experience so much damage.

45 Figs. 8 and 9 show SDC spectra and the ratio SDC/ $\delta$ SD for a multi-story building, for $\zeta=\zeta_{\mathrm{T}}=0.05$, and the

47 response associated with the first mode only. These spectra depend upon parameter $\delta$, which we approximate by $\delta=$

$491.5\left(10 T_{1}\right)$ (see Eq. (25)). From Fig. 9, it can be seen that the amplification factor $\mathrm{SDC} / \delta \mathrm{SD}$ experiences its minimum

51 near the peak of $\delta \mathrm{SD}$ and then grows again for longer $T_{1}$. If we have 10-story structure with $T_{1}=1 \mathrm{~s}, T_{\mathrm{T}}=0.058 \mathrm{~s}$, and

$53 \zeta=\zeta_{T}=0.05$, and we assume that $\beta_{\mathrm{av}}=300 \mathrm{~m} / \mathrm{s}$ and that the building plan dimensions are, say, $\sim 30 \mathrm{~m}$ (100 feet), we

55 will have $\tau \cong(1)(30 / 2) / 300=0.05$. Fig. 9 then shows that 57

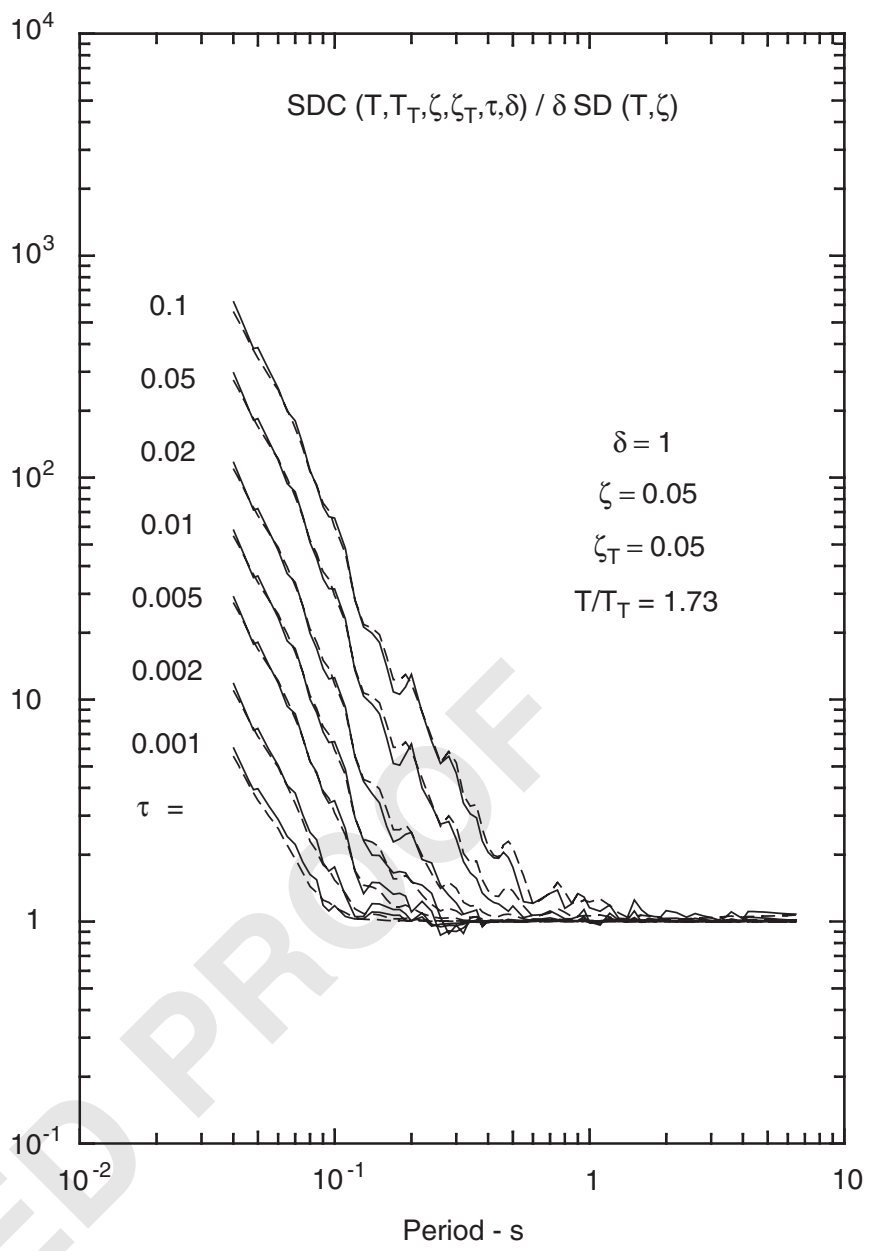

59

61

63

65

67

Fig. 7. Ratio of the new relative displacement spectra for columns and the old relative displacement spectra, SDC $/ \delta \mathrm{SD}$, both shown in Fig. 6 .

maximum shear force relative to the results when wave propagation and strain in the soil are ignored.

For large $\tau$ the maximum relative displacements of the first-story columns are dominated by the pseudo static response to ground deformation, for all periods. This occurs when $\tau_{i}>\delta \operatorname{SD}(T, \zeta) /\left[v_{\max }(1+\delta)^{1 / 2}\right]$, as illustrated in Figs. 8 and 9 for $\tau=0.05$ and 0.10 .

\section{Excitation by short waves}

The forgoing analysis is valid for excitation by waves that are very long relative to the length of structure $L$. This is so because we have approximated the ground motion by a second-order Taylor series of the form

$u_{(t)}=u_{0}(t)+\frac{\partial u}{\partial x} x_{i}+\frac{1}{2} \frac{\partial^{2} u}{\partial x^{2}} x_{i}^{2}$

which involves the average motion $u_{0}(t)$ (see Eq. (3)), linear strain $\partial \mathrm{u} / \partial \mathrm{x}$, and curvature $\partial^{2} u / \partial x^{2}$ terms only. This approximation imposes an upper limit on $x_{i}$, so that $x_{i}<\lambda / 4$, and since $x_{i} \sim L / 2$ it is necessary that $\lambda>2 L$. The two-degree-of-freedom model shown in Fig. 2 can be excited by any ground motion, but then Eq. (1') and Eq. 


\section{ARTICLE IN PRESS}

M.D. Trifunac, V. Gicev / Soil Dynamics and Earthquake Engineering

1

\section{3}

\section{5}

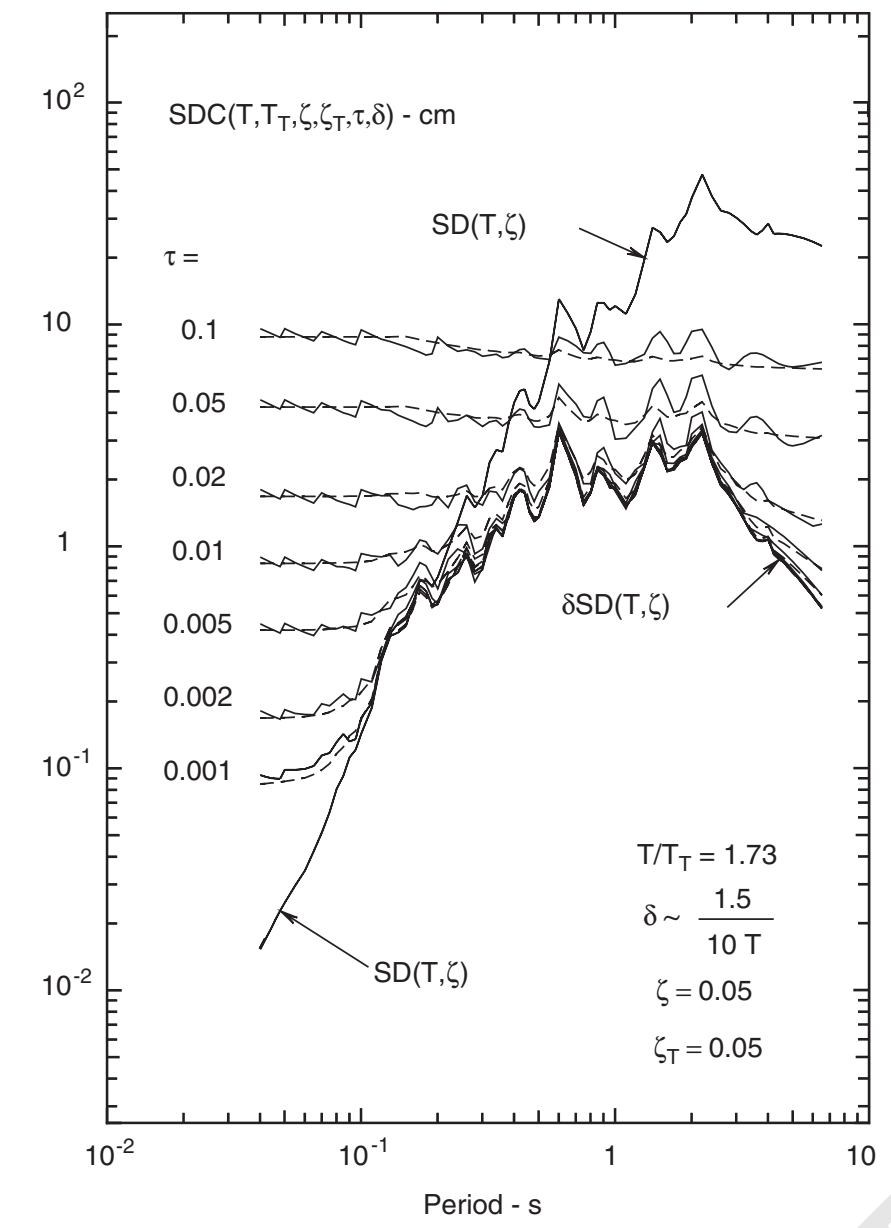

Fig. 8. Same as Fig. 6 but for multi-story buildings. The parameter $\delta$ is a function of the period, $\delta=1.5 / 10 T$.

$\left(2^{\prime}\right)$, must be solved for multiple inputs $u_{i}(\mathrm{t}), i=1,2,3, \ldots, n$. Therefore, Eq. ( $\left.1^{\prime \prime \prime}\right)$ and Eq. ( $\left.2^{\prime \prime \prime}\right)$ will be valid only when the ground motion can be described by average displacement $u_{0}$ and average rotation $\phi_{0}$, which, as has been already noted, is possible when $\lambda \gg 2 L$.

An alternative is to consider a model that can be analyzed using wave-propagation methods. Such a model is shown in Fig. 10. It consists of a two-dimensional slab with two layers, supported by half space, at $y=h_{1}+h_{2}$. For OP waves in the half space, propagating in the $x$ direction, the plate is forced to follow this motion $u(x, t)$ at $y=h_{1}+h_{2}$. The OP response inside the plate $v(x, y, t)$ must satisfy the wave equation

$\frac{1}{\beta^{2}} \frac{\partial^{2} v}{\partial t^{2}}=\frac{\partial^{2} v}{\partial x^{2}}+\frac{\partial^{2} v}{\partial y^{2}}$

where $\rho$ is the density of the plate material and $\mu$ is the rigidity per unit of length, such that $\beta^{2}=\mu / \rho$.

The studies of the response of the model in Fig. 10 using wave-propagation techniques are outside the scope of this paper (e.g., see [23]). Here, we present only an example in order to (1) illustrate the range of the validity of the vibrational approach adopted in this paper and (2) suggest the physical nature of the solution when $\lambda \gg 2 L$ is not

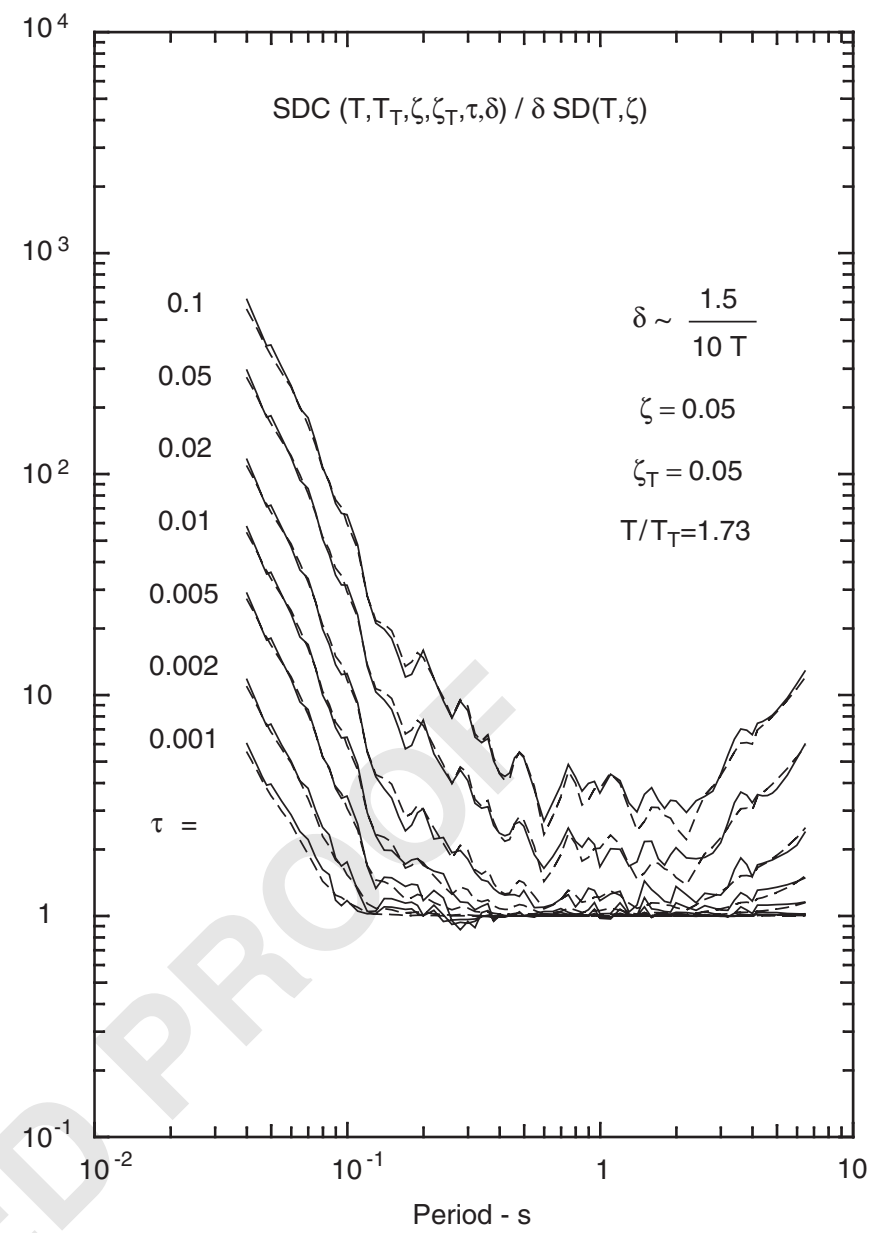

Fig. 9. Ratio of the new relative displacement spectra for columns and the old relative displacement spectra, SDC/ $\delta \mathrm{SD}$, both shown in Fig. 8.

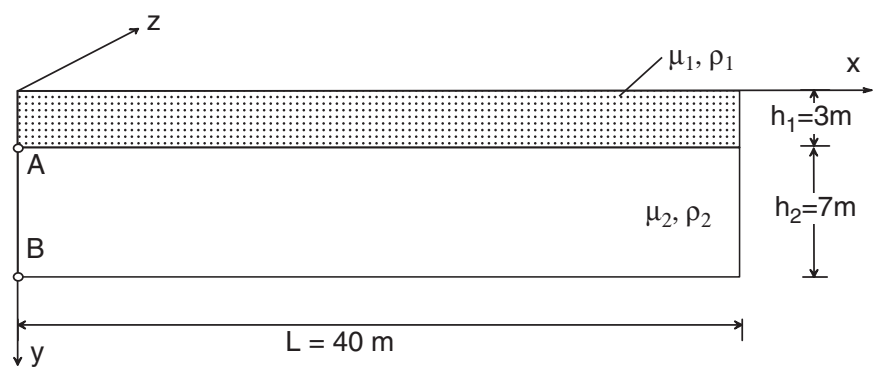

Fig. 10. Continuous two-dimensional analog of the models shown in Fig. $1 \mathrm{a}$ and 2 , represented here by a "soft" layer $\left(\mu_{2}, \rho_{2}, h_{2}=7 \mathrm{~m}\right)$, corresponding to the first story columns, and a "hard" layer $\left(\mu_{1}, \rho_{1}\right.$, $h_{1}=3 \mathrm{~m}$ ), representing the upper part(s) of the structure.

satisfied. To obtain a solution resembling the vibrational 105 solution for the model shown in Fig. 2, we assume that the top layer is essentially "rigid" (we take 107 $\left.\beta_{1}=\sqrt{\mu_{1} / \rho_{1}}=2000 \mathrm{~m} / \mathrm{s}\right)$. The bottom layer is taken to be "soft," so that $\beta_{2}=\sqrt{\mu_{2} / \rho_{2}}=100 \mathrm{~m} / \mathrm{s}$, a value typical 109 of experimentally determined shear-wave velocities in buildings [24,25].

We assume that the motion of the half space consists of a single half-sine pulse, with peak displacement amplitude $a=10 \mathrm{~cm}$ and duration $t_{\mathrm{d}}$, that is propagating with 


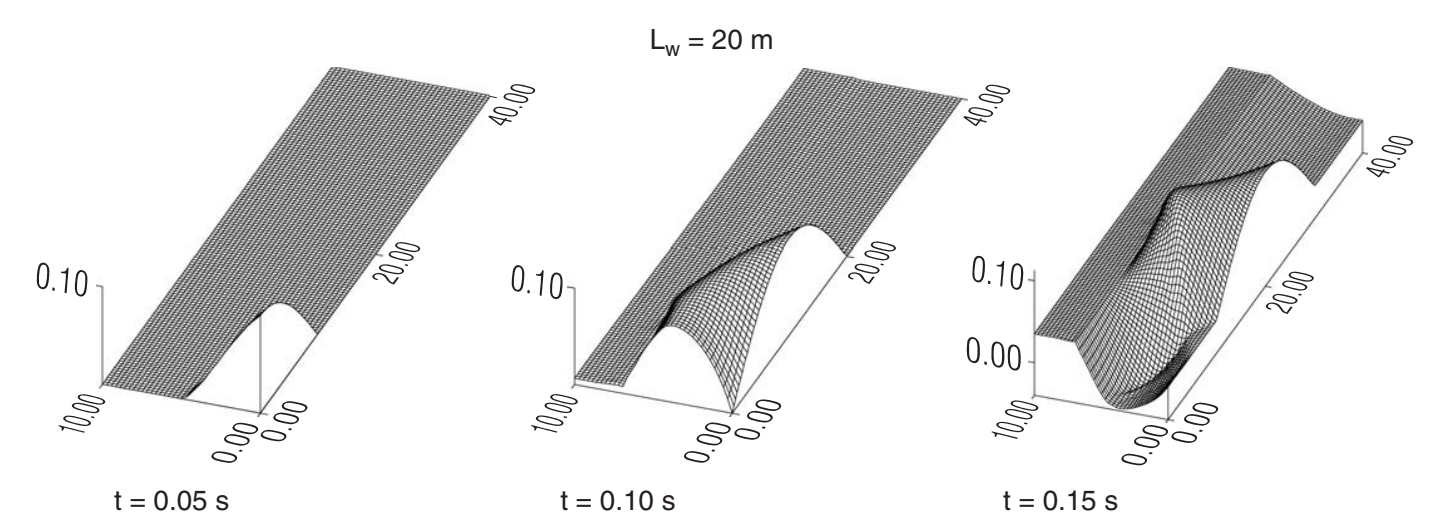

$$
t=0.05 s
$$

$$
t=0.10 s
$$

$$
t=0.15 s
$$
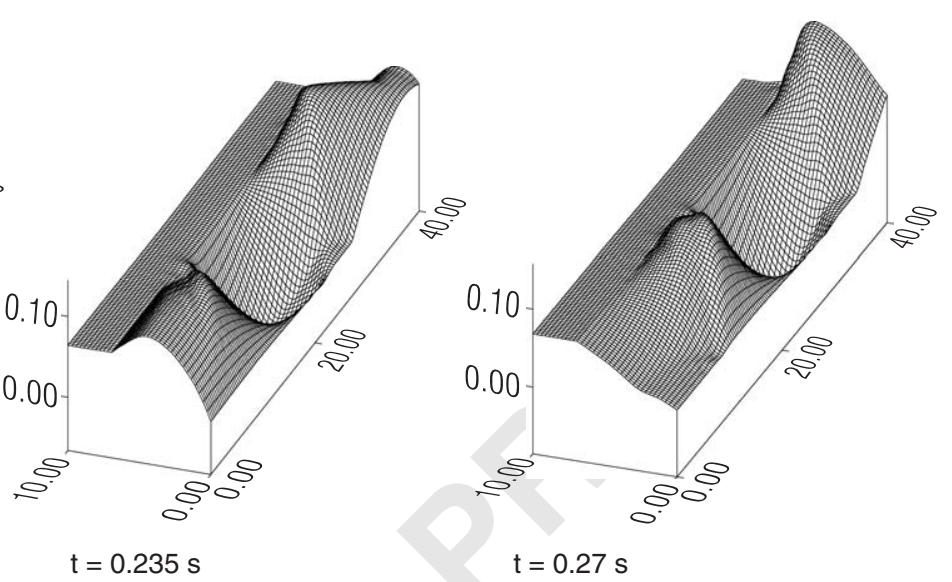

Fig. 11. Out of plane deformation (in $z$ direction) of the model shown in Fig. 10, at six instants $t=0.05,0.1,0.15,0.20,0.235$ and $0.27 \mathrm{~s}$, during passage of ground motion pulse, which propagates along $x$ axis. Pulse duration is $0.1 \mathrm{~s}$, it propagates with horizontal phase velocity of $200 \mathrm{~m} / \mathrm{s}$ and has the wavelength of $40 \mathrm{~m}$.

31 horizontal phase velocity $c$ :

$33 w_{0}=a \sin \frac{\pi}{t_{\mathrm{d}}}\left(t-\frac{x}{c}\right)\left[H\left(t-\frac{x}{c}\right)-H\left(t-\frac{x}{c}-t_{\mathrm{d}}\right)\right]$.

35 The half-wave-length of this pulse is $L_{\mathrm{w}}=t_{\mathrm{d}} c$.

We solve Eq. (29) by the method of finite differences and

37 compute maximum relative displacement between points $A$ and $B$ (see Fig. 10) to simulate the maximum relative

39 displacement of column 1 , at $x_{1}=-L / 2$, in Fig. 2.

Fig. 11 illustrates the nature of the finite difference

41 solution for the model in Fig. 10, excited by the pulse $w_{0}$ in Eq. (30), when $t_{\mathrm{d}}=0.1 \mathrm{~s}, c=200 \mathrm{~m} / \mathrm{s}$, and $L_{\mathrm{w}}=20 \mathrm{~m}$. Fig.

4311 shows the displacement field $v(x, y, t)$ in the "building" at $t=0.05,0.1,0.15,0.2,0.235$ and $0.27 \mathrm{~s}$. At $t=0.05 \mathrm{~s}$, only

45 half of the ground-motion pulse has entered into the building. At $t=0.270$, only its tail is still seen near

$47 x=40 \mathrm{~m}$. As the pulse propagates in the positive $x$ direction, most deformations take place in the "soft"

49 layer. The top "rigid" mass experiences mainly translation and rotation.

51 Fig. 12 shows an example of the relationship between the maximum relative displacement (between points $A$ and $B$ in

53 Fig. 10) computed by finite differences versus the estimate of the same displacement in terms of $v_{\max } \tau$, and for the

55 values $\tau=0.05$ and 0.10 . It can be seen that for $L /$ $L_{\mathrm{w}}=2 L / \lambda \approx 0.15$, or for $\lambda \gtrsim 13 L$, and $\tau=0.1$, the max-

57 imum pseudo-static deformation of the column at $x_{1}=$
$L / 2$ is adequately approximated by $\sqrt{2} v_{\max } \tau$ (see Eq. (17)). As the wavelength in the soil becomes shorter that is, as $L /$ $L_{\mathrm{w}}$ increases the relative motion becomes smaller than $\sqrt{2} v_{\max } \tau$ and asymptotically tends toward " $d_{\max }$ " ( $a$ in Eq. (30) is equal to $d_{\max }$ ) the peak amplitude of the ground displacement pulse.

The example in Fig. 12 confirms that Eq. (27) leads to a good approximation of SDC amplitudes and quantifies the general statement that $\lambda \gg L$ by requiring $\lambda$ to be about one order of magnitude larger than $L$.

\section{Summary and conclusions}

We showed that the linear out-of-plane earthquake response of long structures supported by individual columns, experiencing differential motions at their foundation can be described by a new form of response spectrum. This spectrum is defined (1) for relative displacement of a two-degree-of-freedom system with respect to a point $R$ the displacement of which $u_{0}(t)$ is a weighted average of the motion at the base of the columns, and (2) for torsional response relative to the rotation of ground at $R$ about the vertical axis. For computation of the peak relative displacement of columns that are at a distance $x_{i}$ from the reference point $R$, the six-parameter relative displacement spectra $\operatorname{SDC}\left(T, T_{\mathrm{T}}, \varsigma, \varsigma_{\mathrm{T}}, \tau, \delta\right)$ must be used. Relative 


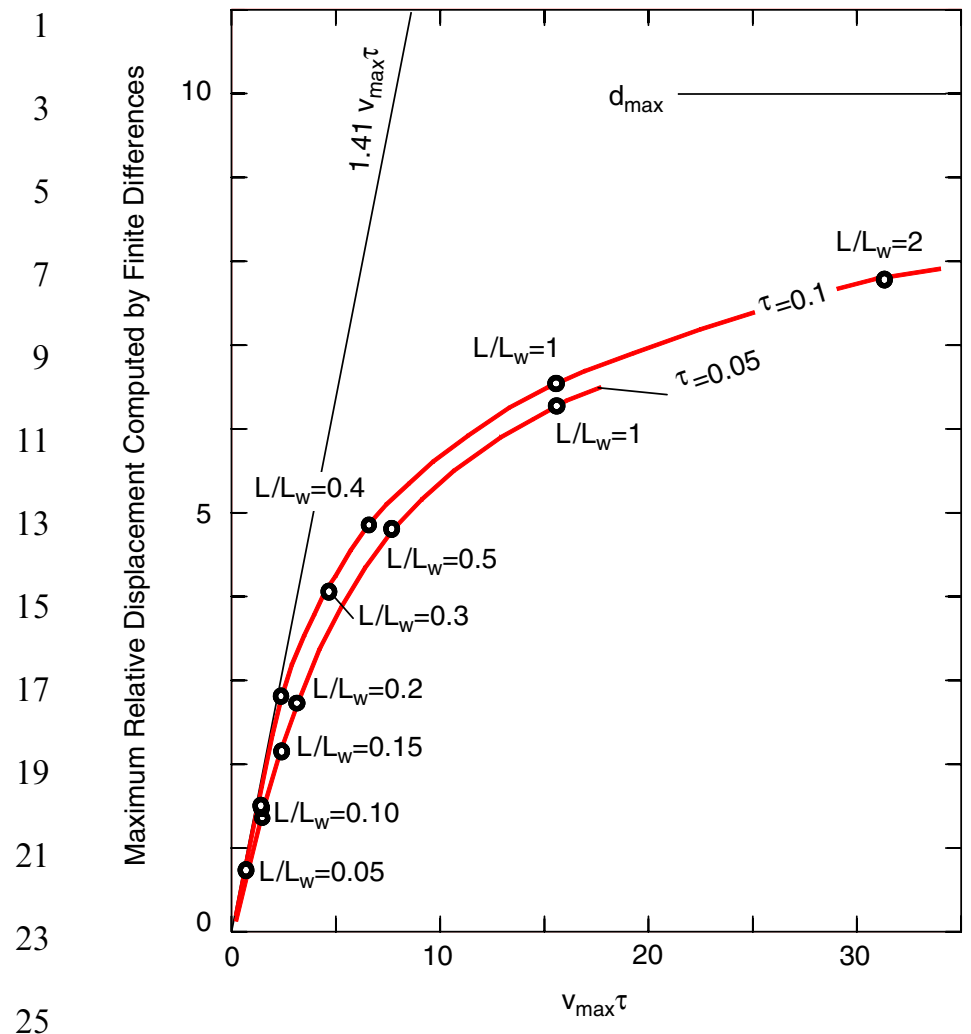

Fig. 12. Comparison of maximum relative displacements $u_{1}$ and $u_{\mathrm{n}}$ at $x_{1}$ and $x_{n}$ of the model shown in Fig. 2, described by straight line, $1.41 \tau v_{\max }$, with maximum relative displacement between points $A$ and $B$, in the corresponding continuous model (see Fig. 10), during passage of ground motion pulse with peak displacement amplitude $d_{\max }=10$, as computed by finite difference. The results for selected ratios of the length of the "building" $L$, and of the pulse, $L_{\mathrm{w}}$, corresponding to $\tau=0.05$ and 0.1 approach asymptotically the slope defined by $1.41 \tau v_{\max }$ as $L / L_{\mathrm{w}} \rightarrow 0$, and the constant $d_{\max }$ as $L / L_{\mathrm{w}} \rightarrow \infty$.

to the classical displacement spectra $\operatorname{SD}(T, \zeta)$ which is defined in terms of two parameters (natural period and fraction of critical damping), four additional parameters are required for SDC: $\delta$, representing the ratio of the peak relative response of the first-story to the response of the equivalent single-degree-of-freedom system; $\tau=s x_{i} / \beta_{\mathrm{AV}}$ proportional to the time required for a wave to propagate from reference point $R$ to the $i$ th column, with velocity of shear waves in the soil beneath the structure $\beta_{\mathrm{Av}} ; T_{\mathrm{T}}$, the torsional period; and $\zeta_{\mathrm{T}}$, fraction of critical damping of the torsional response. Thus defined relative displacement spectrum for the design of columns is valid for ground motions with waves one order of magnitude longer than the length of the structure, $L \sim 2 x_{\max }$.

As already noted in Paper I, the popularity of the classical linear response spectrum method is due to its simplicity, in which all structures are described only by their natural period $T$ and the fraction of critical damping $\zeta$. In Paper I, we showed that the response spectrum method can be extended to apply to the IP response of long structures and to the differential excitation of columns. That extension required the addition of two parameters $(\delta$ and $\tau$ ). In this paper, we showed that with the addition of four additional parameters $T_{\mathrm{T}}, \zeta_{\mathrm{T}}, \delta$ and $\tau$ such a generalization is possible for out-of-plane response as well. In the present formulation, as in Paper I, these additional parameters are not specifically related to the geometry of the structure, the structural system, or the materials used, and therefore our generalization of the response spectrum method maintains the simplicity of the original response spectrum concept. It is hoped that this extension will be useful in design by facilitating estimation of the out-ofplane peak bending and shear forces in the first-story columns of structures.

The amplitudes of the SDC spectrum for out-of-plane response to recorded ground motion can be computed by evaluating relative translation and relative torsion with the Duhamel's integrals $[21,26]$ and then adding the contribution from strain in the ground, and torsional rotation of the ground in terms of the ground velocity $\dot{u}_{0}(t)$ (see Eq. (26)). SDC can also be computed from empirical scaling equations [27-30] for relative spectral displacement, SD ( $T$, $\zeta)$, and peak ground velocity and acceleration $v_{\max }$ and $a_{\max }$ [31,32], using Eqs. (26) and (27). For design applications, SDC spectra can be evaluated for a scenario earthquake or though probabilistic seismic hazard analysis [33-36].

For brevity, in the analysis of multi-story structures we illustrated the relative motion of the first-story, considering only the first mode of response. Using the results and formulation of Gupta and Trifunac [16-19], parameter $\delta$ can be generalized to include the contribution of all modes of the response.

Based on the results presented in Paper I for in-plane motions, and the formulation presented in this paper for out-of-plane motions, we conclude that the concept of response spectrum can be generalized to include the effects of differential ground motions. Modifications are required only for the short-period structures and are very simple to implement in terms of the peak ground velocity, $v_{\max }$, and "travel time," $\tau$, needed for the wave to traverse approximately one-half the length of the structure. These modifications show that the classical response spectrum does not provide conservative estimates for base shear factors of stiff structures, with moderate and large horizontal dimensions, supported by individual columns positioned on soft surface soils.

\section{References}

[1] Bycroft GN. Soil-Foundation Interaction and Differential Ground Motions. Earthquake Eng Struct Dyn 1980;8(5):397-404.

[2] Todorovska MI, Trifunac MD. Note on excitation of long structures by ground waves. ASCE, EMD 1990;116(4):952-64 (and Errata in $116,1671)$.

[3] Trifunac MD, Todorovska MI. Response spectra and differential motion of columns. Earthquake Eng Struct Dyn 1997;26(2):251-68.

[4] Zembaty Z, Krenk S. Spatial seismic excitations and response spectra. J Eng Mech, ASCE 1993;119(12):2449-60.

[5] Trifunac MD. A note on surface strains associated with incident body waves. Bull EAEE 1979;5:85-95. 
1 [6] Trifunac MD. Curvograms of strong ground motion. ASCE, EMD 1990;116(6):1426-32.

3 [7] O'Rourke MJ, Castro G. Effects of seismic wave propagation upon buried pipelines. Earthquake Eng Struct Dyn 1980;8:455-67.

5

8] O'Rourke MJ, Castro G, Hossian I. Horizontal soil strain due to seismic waves. J Geotech Eng Div ASCE 1984;110:1173-87.

[9] Trifunac MD. Response envelope spectrum and interpretation of strong earthquake ground motion. Bull Seism Soc Am 1971;61:343-56.

[10] Newmark NM. Torsion in symmetrical buildings, Proceedings of fourth Word Conference on Earthquake Eng. Santiago, Chile, 1969; A3.19-A3.32.

11 [11] Lee VW, Trifunac MD. Torsional accelerograms. Soil Dyn Earthquake Eng 1985;4(3):132-9.

13 [12] Trifunac MD, Todorovska MI. A note on useable dynamic range in accelerographs recording translation. Soil Dyn Earthquake Eng 2001;21(4):275-86.

15 [13] Trifunac MD. A note on rotational components of earthquake motions for incident body waves. Soil Dyn Earthquake Eng 1982;1(1):11-9.

[14] Yuan SW. Foundations of fluid mechanics. Englewood Cliffs, NJ: Prentice-Hall Inc.; 1967.

19 [15] Lee VW, Trifunac MD. Rocking strong earthquake acceleration. Soil Dyn Earthquake Eng 1987;6(2):75-89.

21 [16] Gupta ID, Trifunac MD. Probabilistic spectrum superposition for response analysis including the effects of soil-structure interaction. $\mathbf{J}$ Probab Eng Mech 1990;5(1):9-18.

23 [17] Gupta VK, Trifunac MD. Response of multistoried buildings to ground translation and rocking during earthquakes. J Probab Eng

\section{Mech 1990;5(3):138-45.}

[18] Gupta VK, Trifunac MD. Response of multistoried buildings to ground translation and torsion during earthquakes. Eur Earthquake Eng 1990;IV(1):34-42.

[19] Gupta VK, Trifunac MD. Seismic response of multistoried buildings including the effects of soil structure interaction. Soil Dyn Earthquake Eng 1991;10(8):414-22.

31 [20] Trifunac MD, Lee VW. Routine computer processing of strongmotion accelerograms, Earthquake Eng. Res. Lab. EERL 73-03. Pasadena, CA: California Institute of Technology; 1973.

33 [21] Trifunac MD, Lee VW. Automatic digitization and processing of strong-motion accelerograms. Department of Civil Engineering, report no. CE 79-15, I, II, Los Angeles, CA: University of Southern California; 1979.

37 [22] Todorovska MI, Trifunac MD, Lee VW, Stephens CD, Fogelman KA, Davis C, Tognazzini R. The $M L=6.4$ Northridge, California, earthquake and five $M>5$ aftershocks between 17 January and 20 March 1994 - summary of processed strong-motion data. Department of Civil Engineering, report no. CE 99-01. Los Angeles, CA: University of Southern California; 1999.
[23] Todorovska MI, Lee VW, Trifunac MD. Investigation of earthquake response of long buildings. Department of Civil Eng., report no. 8802. Los Angeles, CA: University of Southern California; 1988.

[24] Trifunac MD, Ivanovic SS, Todorovska MI. Apparent periods of a building, part I: Fourier analysis. J Struct Eng ASCE 2001;127(5):517-26.

[25] Trifunac MD, Ivanovic SS, Todorovska MI. Apparent periods of a building, part II: time-frequency analysis. J Struct Eng ASCE 2001;127(5):517-26.

[26] Lee VW, Trifunac MD. Automatic digitization and processing of accelerograms using PC. Department of Civil Engineering, report no. CE 90-03. Los Angeles, CA: University of Southern California; 1990.

[27] Lee VW. Empirical scaling of pseudo relative velocity spectra of recorded strong earthquake motion in terms of magnitude, and both local soil and geologic site classifications. Earthquake Eng Vibr 1989;9(3):9-29.

[28] Lee VW. Scaling PSV spectra in terms of site intensity, and both local soil and geological site classifications. Eur Earthquake Eng 1990;IV(1):3-12.

[29] Lee VW. Correlation of pseudo relative velocity spectra with site intensity, local soil classification, and depth of sediments. Soil Dyn Earthquake Eng 1991;10(3):141-51.

[30] Lee VW. Scaling PSV spectra from earthquake magnitude, local soil and geological depth of sediments. J Geotech Eng Div ASCE 1993;119(1):108-26 Can be downloaded from 〈http://www.usc.edu/ dept/civil_eng/Earthquake_eng $>$.

[31] Trifunac MD. Preliminary analysis of the peaks of strong earthquake ground motion-dependence of peaks on earthquake magnitude, epicentral distance, and the recording site conditions. Bull Seism Soc Am 1976;66:189-219.

[32] Lee VW, Trifunac MD, Todorovska MI, Novikova EI. Empirical equations describing attenuation of peaks of strong ground motion in terms of magnitude, distance, path effects and site conditions. Report no. CE 95-02. Los Angeles, CA: Department of Civil Eng., University of Southern California; 1995.

[33] Trifunac MD. Seismic microzonation mapping via uniform risk spectra. Proceedings of ninth world conference on earthquake engineering, vol. 11. Tokyo-Kyoto, Japan, 1988.p. 75-80.

[34] Trifunac MD. A microzonation method based on uniform risk spectra. Int J Soil Dyn Earthquake Eng 1990;9(1):34-43.

[35] Todorovska MI, Gupta ID, Gupta VK, Lee VW, Trifunac MD. Selected topics in probabilistic seismic hazard analysis. Report no. CE 95-08. Los Angeles, CA: Department of Civil Engineering, University of Southern California; 1995.

[36] Todorovska MI, Trifunac MD. Hazard mapping of normalized peak strain in soil during earthquakes-microzonation of a metropolitan area. Soil Dyn Earthquake Eng 1996;15(5):321-9. 